\title{
Differential Effects of Albumin Infusion between ICU and Non-ICU Hypoalbuminemia Patients
}

\author{
Nina Mariana ${ }^{I}$, Surya Oto Wijaya ${ }^{1}$, Rumaisah Setyawati, Siti Maemun ${ }^{1}$, Nafrialdi \\ Nafrialdi ${ }^{2}$ \\ ${ }^{1}$ Sulianti Saroso Infectious Disease Hospital, Jakarta, Indonesia \\ ${ }^{2}$ Department of Pharmacology, Faculty of Medicine, Universitas Indonesia, Jakarta, Indonesia
}

\section{ARTICLE INFO \\ Article \\ submission: 10 \\ Oktober 2021 \\ Revision \\ submission: 24 \\ November 2021 \\ Acceptance for \\ publication: 04 \\ Desember 2021}

Keywords: hypoalbuminem ia, albumin, intensive care unit, sepsis

\section{ABSTRACT}

Background: Hypoalbuminemia is frequent among hospitalized patients and is associated with poor outcomes. ICU patients are widely associated with more severe condition making albumin correction seems to be less effective, while the use of albumin infusion is still high volume and high cost. However, many questions remain regarding which patient groups are most likely to benefit from its use.

Objectives: This study was aimed to compare the results of albumin correction in ICU and non-ICU patients at Sulianti Saroso Hospital, Jakarta.

Methods: A cross sectional study was conducted on adult patients in ICU and non-ICU wards who received intravenous albumin infusion at Sulianti Saroso hospital, between January 2013 to March 2018. The t-test was used to analyze the changes of albumin level infusion in both ICU and non-ICU patients.

Results: 123 ICU patients (41 sepsis, 82 non-sepsis) and 206 non-ICU patients (34 sepsis, 172 non-sepsis) who received $20 \%$ or $25 \%$ albumin infusions were included. Overall, mean increase in albumin levels in ICU-and non-ICU patients were $0.13(0.63) \mathrm{g} / \mathrm{dL}$ vs $0.35(0.54)$ $\mathrm{g} / \mathrm{dL}$, respectively $(\mathrm{P}=<0,001)$.

Conclusion: Non-ICU patients show better response to albumin infusion compared to ICU patients. This difference is presumably due to different degree of inflammation.

Keywords: hypoalbuminemia, albumin, intensive care unit, sepsis 


\section{Introduction}

Albumin is the most abundant protein in the circulation and accounts for about $70 \%$ of the plasma colloid osmotic pressure. Besides for maintaining oncotic pressure, albumin is also important in the transport of drugs especially antibiotic, and other endogenous substances such as unconjugated bilirubin, hormones, etc $(1,2)$.

Hypoalbuminemia is frequent among hospitalized patients especially in critically ill patients and is associated with poor outcomes. Low albumin levels have been associated with higher morbidity and mortality rate in various cases, including myocardial infarction, heart failure, stroke, renal disease, fracture, malignancies, and infections $(3,4,5)$.

Human albumin is widely used for fluid resuscitation in patients with shock, burns, and for correction of hypoalbuminemia condition in ICU and non-ICU patients. Although, its role in improving survival is still controversial, infusion of albumin is widely practiced in clinical setting. Low concentration $(5 \%)$ albumin solution is widely used as plasma expander. In 2013, a Cochrane meta-analysis on 78 trials, showed no evidence of survival benefit of albumin compared to the other crystalloid solutions (6). High concentration (20\% or $25 \%$ ) albumin solutions are used for several indications, such as large volume paracentesis in liver cirrhosis patients, hepatorenal syndrome, major hepatic resection, etc. (7).

Systemic inflammatory conditions such as found in sepsis is common in ICU patients. This condition is resulted from increased vascular permeability and plasma leakage, leading to recurrent hypoalbuminemia and worse response to albumin correction. However, this assumption has not been tested at clinical level. This study was aimed to evaluate the results of albumin correction in ICU patients compared to non-ICU patients.

\section{Methods}

We conducted a cross sectional study. The inclusion criteria were an adult patient (aged $>18$ years old) who received intravenous albumin infusion (human albumin 20 $\%$ and $25 \%, 100 \mathrm{ml}$ ), with at least 2 measurements of plasma albumin levels, before and after albumin infusion. In this study, albumin levels were examined before- and 24 hours after albumin infusions. Albumin infusions are typically available as hyper oncotic $100 \mathrm{ml}$ bottle of $20 \%$ or $25 \%$ solution. Medical records with incomplete data were excluded. The study conducted between January 2013 to March 2018 at the Central of Infectious Disease Hospital, Sulianti Saroso, Jakarta. Based on a total sampling of 747 hypoalbuminemia in hospitalized patients that met the above inclusion criteria were 329 patients. Descriptive information was presented using tables that frequency and percentage were performed to compute the proportion of groups. Patients were divided into ICUpatient group and non-ICU patient groups, and each group were further classified as sepsis and non-sepsis. We used Kolmogorov-Smirnov test to investigate the framing of normality distribution of the numeric variables. The t-test and paired-t-test was used to analyze the changes of albumin levels before and after albumin infusion, withinand between groups. This study protocol has been approved by the ethical committee of the Central Hospital of Infectious Disease, Sulianti Saroso, Jakarta (No.17/xxxviii.10/v/2018). Informed consents were waived due to retrospective nature of the study. We also ensured that all the ethical standards that were used had complied with the principles of the Declaration of Helsinki.

\section{Result}

The characteristic of patients is shown in Table 1. The most frequent $(41.5 \%)$ age group in ICU patient was 18-44 years old, $51.2 \%$ being male patients. Out of 329 patients fulfilled the inclusion criteria, with 123 ICU patients and 206 non-ICU patients. There were $41(33.3 \%)$ patients classified as sepsis and $82(66.6 \%)$ as non-sepsis in the ICU. Meanwhile, the non-ICU patients were consisted of $34(16.5 \%)$ sepsis and $172(83.4 \%)$ non-sepsis.

\begin{tabular}{lcc}
\multicolumn{2}{c}{ Table 1. The characteristic of patients } \\
\hline Variable & $\begin{array}{c}\text { ICU } \\
\mathbf{n = 1 2 3}\end{array}$ & $\begin{array}{c}\text { Non-ICU } \\
\mathbf{n = 2 0 6}\end{array}$ \\
\hline Age (years) & $51(41.5 \%)$ & $143(69.4 \%)$ \\
$18-44$ & $26(21.1 \%)$ & $44(21.4 \%)$ \\
$45-59$ & $39(31.7 \%)$ & $12(5.8 \%)$ \\
$60-74$ & $7(5.7 \%)$ & $7(3.4 \%)$ \\
$>75$ & $63(51.2 \%)$ & $153(74.3 \%)$ \\
\hline Gender & $60(48.8 \%)$ & $53(25.7 \%)$ \\
Male & & \\
Female & $41(33.33 \%)$ & $34(16.50 \%)$ \\
\hline Diagnosis group & $82(66.67 \%)$ & $172(83.50 \%)$ \\
Sepsis & & \\
Non-sepsis & & \\
\hline
\end{tabular}

Severe hypoalbuminemia (albumin level $\leqslant 2.5 \mathrm{~g} / \mathrm{dL}$ ) were found in $71.5 \%$ of ICU patients and $87.4 \%$ of nonICU patients. There were variations in the quantity of albumin infusion between 1 to more than 3 units. The use of 3 or more units of albumin infusion was predominant in ICU patients $(\mathrm{p}<0.000)$. Tabel 2 shows the albumin levels, units of albumin infusion and the variation of types albumin infusion.

Table 2. Albumin levels, units of albumin infusion and the variation of type albumin infusions

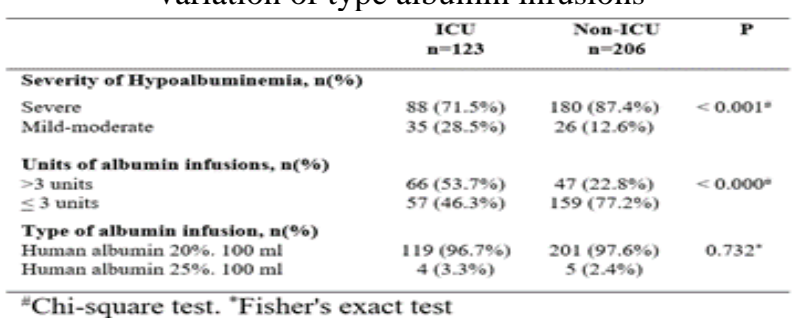


Table 3 describes the changes of plasma albumin levels before and after albumin infusion in ICU and non-ICU patients.

Table 3: Changes of plasma albumin levels before and after albumin infusion in ICU and non-ICU patients

\begin{tabular}{|c|c|c|c|c|c|c|c|}
\hline \multirow[b]{2}{*}{ Albumin level } & \multicolumn{3}{|c|}{ ICU } & \multicolumn{3}{|c|}{ Non-ICU } & \multirow[t]{2}{*}{$\mathrm{p} * *$} \\
\hline & $\begin{array}{l}\text { Sepsis } \\
(\mathrm{n}=41)\end{array}$ & $\begin{array}{c}\text { Non-sepsis } \\
(\mathrm{n}=82)\end{array}$ & $\begin{array}{l}\text { Overall } \\
(\mathrm{n}=123)\end{array}$ & $\begin{array}{l}\text { Sepsis } \\
(\mathrm{n}=34)\end{array}$ & $\begin{array}{c}\text { Non-sepsis } \\
(\mathrm{n}=172)\end{array}$ & $\begin{array}{l}\text { Overall } \\
(\mathrm{n}=206)\end{array}$ & \\
\hline $\begin{array}{l}\text { Before, mean } \\
\text { (SD) gdd }\end{array}$ & $2.00(0.50)$ & $2.31(0.66)$ & $2.21(0.62)$ & $2.12(0.72)$ & $2.00(0.49)$ & $2.02(0.53)$ & \\
\hline $\begin{array}{c}\text { After, mean (SD) } \\
\text { g/dL }\end{array}$ & $2.24(0.43)$ & $2.39(0.49)$ & $2.34(0.47)$ & $2.34(0.60)$ & $2.24(0.48)$ & $2.37(0.51)$ & \\
\hline $\begin{array}{c}\text { Delta, mean (SD) } \\
g / d L\end{array}$ & $0.23(0.41)$ & $0.08(0.72)$ & $0.13(0.63)^{8}$ & $0.22(0.61)$ & $0.38(0.52)$ & $0.35(0.54)=$ & $\begin{array}{l}<0.001 \\
\left({ }^{*} \mathrm{vs}=\right)\end{array}$ \\
\hline $\begin{array}{c}\text { P (before vs. } \\
\text { after) }\end{array}$ & 0.001 & 0.322 & 0.025 & 0.038 & $<0.000$ & $<0.000$ & \\
\hline
\end{tabular}

Overall, the mean of albumin levels before and after albumin infusions were 2.21(0.62) and 2.34(0.47) g/dL in ICU patients $(\mathrm{P}=0.025)$; and $2.02(0.53) \mathrm{g} / \mathrm{dL}$ and $2.37(0.51) \mathrm{g} / \mathrm{dL}$ in non-ICU patients $(\mathrm{P}=<0.000)$. Meanwhile the mean differences of albumin levels in ICU patients and non ICU patients were $0.13(0.63) \mathrm{g} / \mathrm{dL}$ and $0.35(0.54) \mathrm{g} / \mathrm{dL}(\mathrm{P}=<0.001)$, respectively; the changes in non-ICU patients being significantly higher $(\mathrm{P}=<0.000)$..

\section{Discussions}

Hypoalbuminemia is a common problem in some chronic diseases such as liver cirrhosis, nephritic syndrome, malnutrition, as well as in acute critical illness such as septic shock. Numerous previous studies have shown that hypoalbuminemia is associated with poor prognosis. $(8,9)$ Although, the treatment should focus on underlying disease, albumin correction is a common medical practice with the aim to preserve hemodynamic status of the patients. However, limited studies exist to verify whether albumin infusion could increase albumin levels among patients with hypoalbuminemia. Jellinge et al (8) reported that hypoalbuminemia is a strong predictor of 30-day mortality of adult patients with cutely admitted medical conditions. However, another study showed that albumin replacement in addition to crystalloids in patients with severe sepsis, did not improve the rate of survival at 28 and 90 days as compared with crystalloids alone.(9) In our present study, that the proportion of patients with severe hypoalbuminemia on admission was higher in nonICU than ICU group, while mild-moderate hypoalbuminemia was predominated in ICU. In fact, indication for ICU admission was mainly based on clinical severity, rather than on albumin levels.(10 )

In our study, there were variations in the quantity of albumin infusion between 1 unit to more than 3 units. The percentage of patients who received more than 3 units of albumin infusion in ICU group was more than in non-ICU group. Interestingly, the increase of albumin level in response to albumin infusion was prominent in non-ICU patients compared to ICU patients. This increase was mainly contributed by non-sepsis patients, while in sepsis patients, the increase of albumin level was similar between ICU- and non-ICU patients.

According to the changes of albumin levels, the present study showed that albumin levels were significantly increased in both ICU and non-ICU patients, with the overall mean increase of $0.13 \mathrm{~g} / \mathrm{dL}$ in ICU patients and $0.35 \mathrm{~g} / \mathrm{dL}$ in non-ICU patients $(\mathrm{p}<0.001)$. This indicates that non-ICU patients responded better to albumin infusion, although the ICU-patients had received higher quantity of albumin administration. It is interesting to note that the predominant response of non-ICU patients is greatly contributed by non-sepsis group.

There are several factors that might responsible for the different response to albumin infusion between ICU and non-ICU patients. Firstly, the ICU patients are normally associated with more severe condition, in which systemic inflammation is more likely. This condition is related with possible plasma leakage which renders the albumin infusion is more rapidly distributed out of vascular compartment. This assumption is supported by the study of Nadya et al in pediatric sepsis patients which demonstrated that sepsis was a risk factor for lower albumin levels, even after albumin infusion(11).The cytokines released during sepsis may causes an increased in capillary permeability leading to trans-capillary escape rate of albumin of up to $300 \%(12,13)$. Approximately $33 \%$ of intravenous albumin was reportedly leaked into the interstitial space within 5 minutes, and almost all of the albumin escaped from circulation after about 4 hours after infusion(12). In addition, increased catabolisme rate in critically ill patients probably participated in the lower albumin levels after albumin infusion $(12,14)$.

Secondly, the interval between albumin infusion and measurement of plasma albumin level may contribute to different results. In general, human albumin derivatives last only 12-16 hours in the circulation. In the present study, reexamination of albumin level was normally done about 24 hours after infusion. Therefore, a significant amount of albumin might have been leaked out of circulation, giving lower albumin level. In non-ICU patients with notably less severity condition, this leakage is expectedly lesser.

In fact, there are controversies concerning the use of albumin infusion for resuscitation or for correction of hypoalbuminemia. Theoretically, human albumin infusion is considered to have a greater intravascular persistance when compared to crystalloids(14). However, ametaanalysis by Jiang et al reported that albumin infusion did not demonstrate significant advantage for resuscitation in patients with sepsis of any severity(15).This result is supported by a systematic review conducted on 37 clinical trials in 2011 showing no evidence that albumin reduces 
mortality in patients with hypoalbuminemia when compared with saline(16). On the contrary, a meta-analysis published in the same year among 1977 participants showed that the use of albumin-containing solutions for the resuscitation of patients with sepsis was associated with lower mortality compared with other fluid resuscitation regimens(17).

This study has several limitations. The first limitation resides on the cross-sectional design of the study, in which the quantity needed for albumin infusion did not carefully calculated based on patient's clinical conditions. In addition, post infusion level of albumin was taken based on available data, in which the timing of albumin measurement did not set according to kinetics of albumin in the plasma. However, we hope this study may inspire further research to clarify the utilizationof albumin by taking into consideration the degree of severity of the disease, rather than merely based on the difference of albumin level.

\section{Conclusions}

Compared to ICU patients, the non-ICU patients responded better to albumin infusion. This differential response seems to be related to higher degree of inflammation in ICU patients that may lead to albumin leakage.

\section{Acknowledgements}

The authors would like to thank the directors and all of the research team of Sulianti Saroso Infectious Disease Hospital for making this research possible.

\section{Conflict of Interest}

There is no conflict of interest.

\section{Funds}

None

\section{Reference}

1. Caraceni P, Domenicali M, Tovoli A, Napoli L, Serena Ricci C, Tufoni M, Bernardi M. Clinical indications for the albumin use: Still a controversial issue. European Journal of Internal Medicine. 2013; 24:721-8. doi: 10.1016/j.ejim.2013.05.015. Epub 2013 Jun 20.

2. Giancarlo L, Francesco B, Gina R. Recommendations for the use of albumin and immunoglobulin. Blood transfusion. 2009.27: 216-234.doi: 10.2450/2009.009409

3. Cheng HC, Yang EH, Wu CT, Wang WL, Chen PJ, Lin
MY, et al . Hypoalbuminemia is predictor of mortality and rebleeding in peptic ulcer bleeding under proton pump inhibitor use. Journal of the Formosan Medical Association (JFMA). 2018;117: 316-25. doi: 10.1016/j.jfma.2017.07.006. Epub 2017 Jul 24

4. Mi Yeon, Sung WL, Seon HB, Ki young, Dong WC, Ho jun, Sejoong K. Hypoalbuminemia at admission predicts the development of acute kidney injury in hospitalized patients: A retrospective cohort study. PLoS One. 2017 Jul 19;12(7): e0180750. doi: 10.1371/journal.pone.0180750. eCollection 2017.

5. Zusman O, Farbman L, Tredler Z, Daitch V, Leibovici A. Paul M. Association between hypoalbuminemia and mortality among subjects treated with ertapenem versus other carbapenems: prospective cohort study. Clinical Microbiology and Infection (CMI). 2015 Jan;21(1):548. doi: 10.1016/j.cmi.2014.08.003. Epub 2014 Oct 12.

6. Perel P, Roberts I, Ker K. Colloids versus crystalloids for fluid resuscitation in critically ill patients. The Cochrane Database of Systematic Reviews (CDSR). 2013;28(2):CD000567. doi:0.1002/14651858.CD000567

7. Benefit L, Benefit M. Guidelines for Intravenous Albumin Administration at Stanford Health Care Policy. Stanford Health Care Pharmacy Department. Created: 03/2017

8. Jellinge ME, Henriksen DP, Hallas P, Brabrand M. Hypoalbuminemia is a strong predictor of 30-day allcause mortality in admitted medical patients: a prospective, observational, cohort study. PlosOne. 2014,9:e105983. doi: 10.1371/journal.pone.0105983

9. Lyons O, Whelan B, Bennett K, O'Riordan D, Silke B (2010) Serum albumin as an outcome predictor in hospital emergency medical admissions. The European Journal of Internal Medicine. 21: 17-20. doi: 10.1016/j.ejim.2009.10.010

10. Caironi P,Tognoni G, Masson S,Fumagalli R,Pesenti A, Romero $\mathrm{M}$ et al.Albumin replacement in patients with severe sepsis or septic shock.New England Journal of Medicine.2014;370(15):1412-21.doi:

10.1056/NEJMoa1305727. Epub 2014 Mar 18.

11. Behzad M, Seyed H, Amin A. A model for decision making for intensive care unit admission source limited hospitals. Iran Red Crescent Medical Journal. 2014;16(10):e15497.

12. Arafuri N, Widjajanto PH, Haksari EL. Risk factors for the failure to achieve normal albumin serum levels after albumin transfusions in neonates. Paediatrica Indonesiana.2016; 56:129-33

13. Quinlan GJ, Margason MP, Muraby S, Evans TW, Gutteridge JM. Administration of albumin to patients with sepsis syndrome: a possible beneficial role in plasma thiol repletion. Clinical Science (London) 1998; 95 (4): 459-65.

14. Falco H, Japiassu AM. Albumin in critically ill patients: controversies and recommendations. Revista 
Brasileira de Terapia Intensiva.2011: 23:87-95

15. Mitra S, Khandelwal P. Are all colloids same? How to select the right colloids? Indian Journal of Anaesthesia. 2009;53(5):592-607.

16. Jiang L, Jiang S, Mao Zhang M, Zheng Z, Ma Y. Albumin versus Other Fluids for FluidResuscitation in Patients with Sepsis: A Meta-Analysis. PLoS ONE. 9(12): e114666. doi: 10.1371/journal.pone.0114666: 2014.

17. Alderson P, Bunn F, Li WP, Pearson M, Robert J, Schierhout G. Human albumin solution for resuscitation and volume expansion in critically ill patients. The Cochrane Database of Systematic Reviews (CDSR). 2011;9: CD001208. doi: 10.1002/14651858.CD001208.pub4

18. Delaney AP, Dan A, McCaffrey J, Finfer S. The role of albumin as a resuscitation fluid for patients with sepsis: a systematic review and metaanalysis. Critical Care Medicine.2011; 39 38691.doi: 10.1097/CCM.0b013e3181ffe217. 